\author{
Maria C. Yang ${ }^{1}$ \\ Daniel J. Epstein Dept. of Industrial \& Systems \\ Engineering, \\ University of Southern California, \\ Los Angeles, CA 90089 \\ e-mail: maria.yang@usc.edu \\ Jorge G. Cham \\ Department of Mechanical Engineering, \\ California Institute of Technology, \\ Pasadena, CA 91125 \\ e-mail: jgcham@caltech.edu
}

\title{
An Analysis of Sketching Skill and Its Role in Early Stage Engineering Design
}

Previous studies have demonstrated the importance of sketching in design cognition, particularly in the early stages of engineering design. The goal of this preliminary study is to consider the role of a designer's sketching ability and to examine the potential link between sketching skill and measures of engineering design performance. Sketching ability was evaluated on three distinct aspects relevant to engineering design: visual recall, rendering, and novel visualization. These evaluations were correlated with each other and with measures for sketch fluency, reviewer ranking, and design project outcome. The results of this study suggest that sketching skill is not comprehensive nor is it solely task based. Rather, a designer's sketching ability lies between these two poles. Positive correlations were found between the quantity of sketches produced and two of the sketching skills that emphasize drawing facility, but a negative correlation was found between sketch quantity and a skill related to mechanism visualization. No conclusive correlations were found between the sketching skills and design outcome and reviewer ranking. This study's findings suggest an important interplay between a designer's ability to sketch and their ability to visualize in their heads or through prototypes. Results also suggest that designers who are given sketch instruction tended to draw more overall.

[DOI: 10.1115/1.2712214]

Keywords: engineering design, sketching, design process, design teams

\section{Introduction}

Sketching is an activity that often takes place throughout the engineering design process and is valuable for both capturing and communicating design ideas $[1,2]$. The significance of representing design concepts through sketches has been discussed in depth by many theorists [3-7]. In particular, sketching has been closely linked with promoting design thinking and creativity [8-10]. In fact, sketching is often thought of as a "language" for design in which the designer maintains a dialogue with the external representation [11-14]. Iteration, a key activity in design [15], is apparent during sketching and is believed to indicate the occurrence of new design knowledge [16,17].

If sketching is the language of design cognition, it would seem that proficiency in that language might impact both the design process and performance. Broadly speaking, what is the role of sketching skill in engineering design? This paper considers four aspects of sketching in the context of design, including the nature of sketching skill, its relation to design outcome, the influence of sketching instruction in sketching skill, and how sketching skill relates to team project documentation. It is based on preliminary research presented earlier by the authors [18]. Specific questions this research examines include the following:

1. What is the nature of sketching skill in the context of engineering design? Is drawing ability an innate, universal skill ("he's a good sketcher, he can draw anything") or are differences in ability defined at a lower level?

Because sketching is, in part, a reflection of the cognitive activities of the designer, it is instructive to refer to research in mental imagery ability to develop a framework for understanding

${ }^{1}$ Corresponding author.

Contributed by the Design Theory and Methodology Committee of ASME for publication in the Journal of Mechanical Design. Manuscript received December 31, 2005; final manuscript received May 19, 2006. Review conducted by Clive L. Dym. Paper presented at the ASME 2005 Design Engineering Technical Conference and Computers and Information in Engineering Conference (DETC2005), September 24-28, 2005, Long Beach, California, USA. sketching skill. Mental imagery is defined as the recall of an image stored in memory, and drawings are conceptions of these mental images. Kosslyn [19-21] describes three possible views of mental imagery ability: (i) Imagery ability is an innate, comprehensive "trait;" An individual is either "good" or "bad" at all types of imagery. (ii) Imagery ability is a task-based skill; an individual may perform well on one imagery task but may not necessarily perform well on another task. (iii) Imagery ability is defined somewhere between (i) and (ii) such that some subsystem of imagery skills are drawn on for specific tasks. Kosslyn's work [19-21] supports the third option as an appropriate model of mental imagery skill.

This study hypothesizes that sketching ability can be described in a similar fashion and that not all sketching skills are created equal in the context of the engineering design process. An individual who might excel at rendering a realistic object placed in front of them might not be as good at drawing a similar object from memory. Distinct sketch tasks were given to designers to assess their facility with each, and to understand the relationship, if any, between the various skills.

2. How is sketching ability linked to the design process, in particular, with sketch fluency and design outcome? It is surmised that someone who has a high level of drawing facility might perform better on some measures of design outcome. First, it is hypothesized that those who draw better also draw more while engaged in the engineering design process. Second, this paper considers whether higher drawing facility has a positive correlation with design performance.

3. What is the role of sketch instruction in design outcome? From an educational point of view, design activity involves different types of intelligences. Gardner [22] describes logicalmathematical and spatial intelligences that are consistent with the skills needed by successful engineering designers. Painters, in contrast, are typically assumed to be stronger primarily in the spatial intelligence.

Engineering students traditionally are assessed on their mathematical and verbal abilities and less by their visualization skills. 
Many engineering undergraduates in the United States are instructed in drafting and computer-aided design (CAD), but rarely in sketching. Does the teaching of sketching skills correlate with better design? Understanding the role of sketching in design will provide insights for better design education and better interpretation of observable design activity in our quest to understand the design activities and cognitive processes that occur during the design process.

4. How does sketching skill relate to how a team accomplishes its group work? Much of engineering design takes place in the context of a team in which individuals have complementary functional, problem-solving, and interpersonal skills [23]. Sketching relates to all three of these aspects of teaming in that it is a functional skill, is an important element of design cognition, and further operates as a communication medium among team members as well as a shared repository of ideas for the collective group [1]. The question this study poses is: Do individuals with stronger drawing skills contribute more sketching to group design documentation than their teammates with weaker drawing skills?

\section{Related Work}

2.1 Sketch Classification. There is little research that specifically considers sketching skill in engineering design. However, there has been much research in classifying sketches by type or function. Ullman [1], Ferguson [24], and van der Lugt [25] formulated categories that can be described generally as thinking sketches that aid in cognition, prescriptive sketches that serve as a blueprint for design work, talking sketches that provide a focus for design team discussion, and storing sketches that are a repository for ideas. Goel [5] classifies sketches as incremental or refining idea transformations. Other work has labeled sketches by the physical elements of the sketch (shading, dimensions, annotation, etc.), which are typically independent of the content and meaning of the sketch itself [26,27]. None of these approaches, however, consider the quality of a particular sketch or the drawing abilities of the designer.

2.2 Sketching and Design Outcome. Sketching as an activity has been linked to design outcome in other studies. Schütze et al. [28] found that design teams who were permitted to sketch while coming up with a design produced a higher-quality solution than those who were deprived of the opportunity to sketch. Song and Agogino [29] observed the positive relationship between the amount of three-dimensional (3D) perspective sketching and design outcome. Yang [30] found that the quantity of dimensioned drawings created early in the design cycle is significantly linked with design outcome. Ruder and Sobek [31] consider the link between system-level design activities, including sketching, and time profiles of design. However, there is no research about the individual's assessed drawing skill and how it might relate to design outcome.

\section{Methods}

To explore the research questions presented, this preliminary study assessed the sketching ability of a group of undergraduate novice designers (predominantly juniors) using a set of sketching tasks that take into consideration these different aspects of sketching ability. Performance on the sketching tasks was then correlated with design sketch activity, as captured by their design log books, and also correlated with design outcome in a four-week engineering design class project at the California Institute of Technology. The impact of teaching sketching skills on sketching activity by looking at differences in sketch fluency for a subset of the students, who enrolled in a sketching and CAD course taught during the same quarter, was explored. Finally, the role of sketching-ability team project documentation was considered.

3.1 Survey of Sketching Ability. At the beginning of the term, students completed a survey to assess their drawing skill.
The survey presented the students with two questions followed by three sketching tasks. The students were given approximately 10 min to complete the following survey:

1. Do you consider yourself good at drawing? (multiple choice answer: "nope," "not really," "kind of," "yes," and "you betcha").

2. List previous experience with drawing/sketching (hobby, classes, etc.).

3. In three minutes, draw a bicycle with as much detail as possible.

4. Hold out the items given to you in your nondominant hand (left hand for right-handed persons). In $3 \mathrm{~min}$, make a drawing of your hand and the items (items given were two small candy bars).

5. Visualize and draw the following in 2 min: A rectangular box that is open at the top. Inside the box is a rubber ball. The front of the box has a large button, and each side of the box has a large " $\mathrm{X}$ " painted on it.

These sketching tasks were designed to emphasize different hypothesized aspects of sketching ability that may be applied during the engineering design process:

- Mechanical recall. Sketching a bicycle from memory emphasizes the ability to recall and visualize nontrivial functional mechanical structures and mechanisms. It was assumed that most, if not all, students had seen and likely ridden a bicycle, so that it was a familiar object. This task directly tested the ability to activate information stored in memory as mental images.

- Drawing facility. Sketching an organic object from a live model emphasizes the ability to create clear, realistic, wellcomposed drawings, as the task requires little imagination or ability to visualize.

- Novel visualization. Sketching a three-dimensional object from a verbal description emphasizes the ability to visualize novel objects by merging three simple, familiar objects.

These proposed aspects of sketching ability seek to decouple some of the different skills necessary in translating and transforming ideas in mechanical design into visual representations. For example, mechanical recall is a skill that may be more related to a person's ability to grasp and manipulate spatial constructions, while drawing facility is hypothetically more related to a person's hand-eye coordination, sense of visual balance and practice in sketching.

3.2 Assessment of Sketching Skills. Sketching ability in the engineering design process is challenging to consider, in part, because of the subjectivity of what constitutes a "good" or a "bad" sketch. Aspects of sketches that are often taken into account are representational accuracy (realism), drawing style, and level of detail. In this study, performance on the sketching tasks was assessed by first determining a clear scoring criterion for each task and then binning each sketch into one of five levels of performance according to that criterion. Sketches were judged independently by three judges (sketching judges) with professional backgrounds in product design and engineering. Sketches for each task were graded separately. Figure 1 shows representative examples of the sketches for each task.

The bicycle recall task was graded on the basis of whether the sketch demonstrated a clear grasp of the concept, structure, and operation of a bicycle (Does this look like a bicycle? Are the essential components, such as a frame, wheels, chain, etc., present? Are these components connected in such a way that it is believable that this bike could work mechanically?). The bicycle task is of particular interest in the context of mechanical design because mechanical engineering students are likely to possess a natural affinity for mechanical devices. The live model task was graded on the basis of the sketch's accuracy on proportions of the 
Level 1
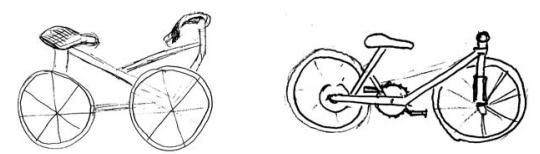

Mechanical Recall Task
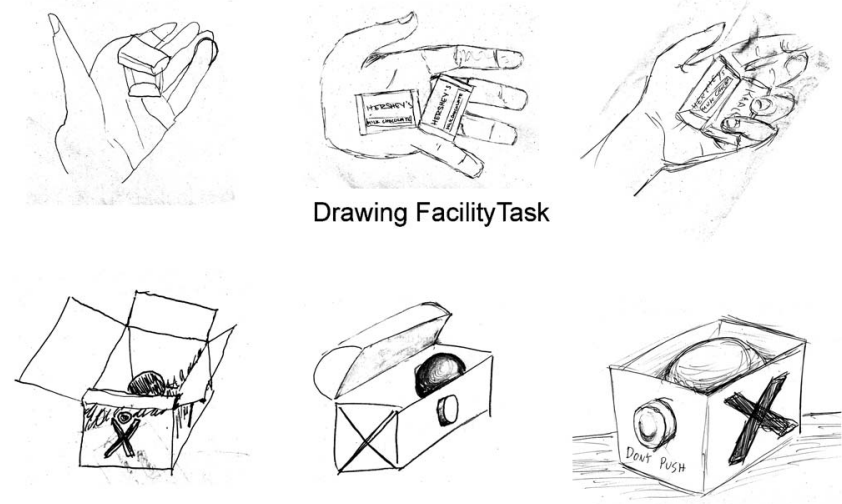

Novel Visualization Task

Fig. 1 Representative drawings for the three sketch tasks. Level 1 demonstrates lowest drawing facility, while level 5 shows highest facility.

hand, realism, and level of sketch detail (Does this look like a hand?). The box visualization task was graded on the basis of correct proportion of the object, accuracy of three-dimensional perspective and overall realism (Does it seem like the ball actually sits correctly in the box?).

3.3 Sketch Fluency. There are a number of ways that ideas might be assessed in sketch, such as the range of sketches explored and the innovativeness of a particular idea. This study focuses exclusively on the volume of ideas, in part, because it is a relatively objective yet informative measure.

For the final project, each student worked individually or in teams of up to four people. Over four weeks, each team/individual selected a project from a preapproved list of mechanical design projects (e.g., a can opener) or proposed their own project (e.g., a spice and condiment dispenser) subject to approval by the instructors, then designed and built their design in the machine shop. Two representative projects from the course are shown in Fig. 2. One is a multiwheeled vehicle, the other is a mechanical system for simulating the motion of a fish fin. The instructors included a scaling factor for the grade based on their assessment of the project difficulty and scope, and the individual student or team's capabilities.


Fig. 2 Sample projects from surveyed engineering design course: Left, multiwheeled vehicle and right, mechanical prototype to simulate motion of fish
To understand the students' drawing fluency (quantity of drawing), this study examined the paper design logbooks each student kept for the course's final project. All students were given basic guidelines on the use of logbooks as a repository of ideas. Logbooks are unique in these courses because they are primarily an individual medium, rather than a collaborative platform. The logbook is an archive of the individual design dialogues of each student designer and, thus, a comprehensive recording of their design thinking that can serve as a useful archive for understanding design activity. Many of the drawings in logbooks were fragmentary, informal line drawings (both two-dimensional (2D) and 3D), with little detail or shading, that appear to be "thinking" drawings. This is consistent with the findings in the study by Song and Agogino [29] in which the vast majority of sketches were thinking drawings. This suggests that the logbook drawings were intended for the designer himself, rather than for presentation to the greater team.

During the final project, each individual was asked to maintain a logbook of their design ideas in text and sketches. Students were informed that use of the logbooks would constitute a small percentage of their overall grade. Each sketch included in the logbook was counted individually. On some occasions, sketches from other team members were inserted into another's logbook, and these sketches were not included in the count. In this preliminary study, the quality, type, and content of the logbook sketches were not considered, only the raw number of drawings were.

3.4 Role of Sketching Instruction. To explore whether the explicit instruction of sketching skills can be linked to design activity, we analyzed differences between the two following subsets of the students involved in the study:

Without sketch instruction: This included 18 students enrolled in the introductory mechanical engineering design course previously described. Students learned design methodologies, basic machine shop skills, and were given three hands-on, open-ended design projects over the quarter.

With sketch instruction: This included 14 students also enrolled in the same above-mentioned mechanical engineering course and simultaneously enrolled in a unique course that allowed students to practice their sketching skills and also taught them to use a CAD software package. The course consisted of weekly in-class demonstrations of sketching techniques for perspective drawing of complex rectangular and curved objects, shading techniques, drawing of simple human figures, sketches to communicate the senses of action and emotion, storyboarding, and techniques for illustrating mechanisms. Sketch instruction took place during the first half of the school quarter, while the final engineering design project took place in the second half. Students thus had sketch instruction prior to the final design project, with a small amount of overlap. During the second half of the quarter, the demonstrations were on basic CAD techniques for creating common 3D shapes, assemblies, and engineering drawings. Weekly homework was assigned to students to practice sketching and CAD skills.

3.5 Design Project Outcome. The quality of the final design projects were assessed through final project grades and by the evaluation of two external design judges who are practicing mechanical design engineers in industry (project judges). Each judge separately examined the final project devices for their design, functionality, and level of craftsmanship, and then rank ordered the projects. The final project grades were assessed by the instructor of the course (not the authors) and were computed independently of the judges' rankings.

3.6 Correlation. The Spearman Ranking Correlation [32] for nonparametric populations was used to test for correlations between the different data variables. The Spearman correlation coefficient $R_{s}$ is computed as follows: 
Table 1 Correlation between sketch tasks: $N=32, R_{s} \geqslant 0.296$ for $\alpha=0.10$

\begin{tabular}{lc}
\hline \hline & Correlation coefficient, $R_{s}$ \\
\hline Bike and hand & 0.193 \\
Bike and box & 0.055 \\
Hand and box & 0.243 \\
\hline \hline
\end{tabular}

$$
R_{s}=1-\frac{6 \cdot \sum_{i=1}^{N} d_{i}^{2}}{N^{3}-N}
$$

where $N$ is the sample size and $d_{i}=X_{i}-Y_{i} . X$ and $Y$ are the ordinal ranks of the variables being correlated, in this case design data and design outcome. $R_{S}$ can take on a value between -1 and 1 . If $-1<R_{s}<0$, then there is a negative correlation between the two data sets. If $0<R_{s}<1$, then there is a positive correlation. In this study, 32 of 33 students completed the sketch survey; thus, in experiments that considered sketching skill assume $N=32$ students, the correlation is considered statistically significant if $R_{s}$ $\geqslant 0.296$ for a significance level, or a probability of error, of $\alpha$ $=0.10$ (two tailed). For experiments that do not consider sketching skill, $N=33$ students, $R_{s} \geqslant 0.291$ for $\alpha=0.10$ (two tailed).

\section{Results and Discussion}

4.1 Aspects of Sketching Ability. Table 1 shows the correlation coefficients between the average judged scores in the three different sketching tasks. "Bike" refers to scores in the bicycle recall task, "Hand" refers to scores in the live model drawing task, and "Box" refers to scores in the box visualization task. Note that there was strong agreement on the ratings for the three tasks among the three sketching judges. The pairwise correlations between ratings from each of the judges were all statistically significant, ranging from 0.85 to 0.89 for the bike task, 0.63 to 0.85 for the hand task, and 0.60 to 0.72 for the box task.

Consider these results in the context of Kosslyn's [19-21] logic for mental imagery ability. There are three likely expected results for correlations. First, if sketching is an innate, comprehensive skill (an inherent trait of an individual), that is, some individuals are always good at sketching while others are never good at sketching, then it would be expected that sketch tasks (bike, hand, and box) would be highly correlated. Being good at one task means being good at all tasks. Likewise, poor performance at one task would mean poor performance across all tasks.

The second possible scenario would be that sketching skill is task based, meaning that some individuals are strong at certain sketch tasks (the bike, for example) but not at others. If this were the case, there would be no (zero) correlation between the sketch tasks.

However, the results suggest a third scenario, similar to the third theory proposed by Kosslyn [19-21], that sketching skill lies somewhere between the two scenarios. The correlations are somewhere between uncorrelated and strongly correlated, ranging from 0.055 to 0.243 between the tasks.

Of the three tasks, the hand and box tasks have positive (but not statistically significant) correlations, while the bike task has lower correlation with the hand task and is effectively uncorrelated with the box task. Doing well in one task does not correlate with doing well in the other tasks. In other words, it appears that the skills required for each task are somewhat, but not wholly, independent. Independence between the different skills supports their selection as distinct aspects of sketching ability that are distributed differently among the surveyed participants.

4.2 Sketching Ability and Sketch Fluency. What is the relationship between the various individual sketching tasks and the
Table 2 Sketching tasks and sketch quantity: $N=32, R_{s}$ $\geqslant 0.296$ for $\alpha=0.10$. Statistically significant correlations are in bold.

\begin{tabular}{lcc}
\hline \hline & \multicolumn{2}{c}{ Correlation coefficient, $R_{s}$} \\
\cline { 2 - 3 } & $\begin{array}{c}\text { Total } \\
\text { sketches }\end{array}$ & $\begin{array}{c}\text { Perspective sketches } \\
\text { only }\end{array}$ \\
\hline Bike & 0.153 & -0.216 \\
Hand & $\mathbf{0 . 2 9 6}$ & 0.222 \\
Box & $\mathbf{0 . 2 8 9}$ & 0.084 \\
\hline \hline
\end{tabular}

quantity of sketches produced in each participant's design logbook? Table 2 shows there is a distinct difference in correlation with sketch fluency between scores in the bike task and scores in the hand and box tasks. Both hand and box tasks are significantly correlated $(\alpha=0.10)$ with the total number of sketches. This implies that drawing well in a general sense correlates positively with total sketch output (the total amount of hand-drawn visual information recorded in their logbooks). In this case, it appears that performance in the bicycle recall task is uncorrelated with total sketch output.

Correlations with the number of perspective sketches show interesting results. Scores in the hand task correlated positively with the total number of perspective sketches. However, scores in the bike task correlated negatively with the total number of perspective sketches. In other words, participants who demonstrated a capacity to accurately recall nonsimple mechanical structures and mechanisms were less likely to draw three-dimensional perspective sketches.

Although these results are still preliminary, the differences in correlation between scores in the bike and hand tasks suggest the following observation: What designers choose to put down on paper seems to depend on an interplay between how well they can draw (high score on the hand task), and how much they need to draw (low score on the bike task). Having facility at drawing may make a designer more likely to use sketches in design, but only if he/she lacks skill in recalling and visualizing complex mechanisms. Conversely, a designer with talent for mentally grasping mechanisms but with poor facility for drawing may be more likely to choose to work out the design in his/her head, and not utilize sketches at all.

This theory is given credence from the work of Song and Agogino [29], which found that logbook sketches tend to be largely "thinking" sketches. It is inferred that those who tend to perform well in the hand and box tasks tend to "think" in their logbooks, while those who "work things out in their head" tend to draw less.

4.3 Sketching and Design Outcome. The above results indicate that there are somewhat different skills involved in sketching ability and that these skills together may influence how likely a designer is to use sketches in their design thinking. The next question is whether these differences influence design outcome, as measured by project grade, overall class grade, and average project reviewer ranking.

It is interesting to consider the consistency of the three metrics of design outcome, as measured by the correlation among the three metrics. The correlation between project grade and overall class grade was, not surprisingly, statistically significant $\left(R_{s}\right.$ $=0.89)$. In addition, the rankings of the two outside project judges also correlated in a statistically significant way with each other $\left(R_{s}=0.59\right)$. However, both judges' rankings correlated negatively with project grade $\left(R_{s}=-0.22\right)$, perhaps because project grades take into consideration the process involved in developing a project, while the reviewers rankings are solely based on responses to the final device itself.

Table 3 shows the correlation coefficients between sketch fluency for total sketches and perspective sketches only, and design 
Table 3 Sketches by type and design outcome: $N=33, R_{s}$ $\geqslant 0.291$ for $\alpha=0.10$

\begin{tabular}{lccc}
\hline \hline & \multicolumn{3}{c}{ Correlation coefficient, $R_{s}$} \\
\cline { 2 - 4 } & $\begin{array}{c}\text { Project } \\
\text { grade }\end{array}$ & $\begin{array}{c}\text { Overall } \\
\text { class } \\
\text { grade }\end{array}$ & $\begin{array}{c}\text { Avg. project } \\
\text { reviewer } \\
\text { ranking }\end{array}$ \\
\hline Total sketches & 0.170 & 0.182 & 0.132 \\
$\begin{array}{l}\text { Perspective } \\
\text { sketches only }\end{array}$ & 0.012 & 0.084 & 0.267 \\
\hline \hline
\end{tabular}

outcome as measured by the three metrics described. In terms of sketch fluency, there are positive but not significant correlations between the total number of hand-drawn sketches and all three design outcome measures. Perspective sketches are thought to reflect more developed sketching skills. These results show that such sketches are almost uncorrelated with project or overall grade, but positively correlated with the ranking given by the project judges.

Table 4 shows the correlation coefficients between the three sketching tasks and the design outcome measures. Overall class grade is virtually uncorrelated with any sketching skill, and the average project reviewer ranking is either negatively correlated or uncorrelated with sketching skill. Project grade is positively correlated with the box task (novel visualization), which is most closely associated with design synthesis but is uncorrelated with the remaining two tasks.

Overall, these results show no clear trend of correlation between sketch fluency and design outcome or between sketch ability and design outcome for the three sketching tasks and outcome measures examined. It should be emphasized that in this study, the three design outcomes were not consistent with each other, making it difficult to draw more reliable conclusions. In this particular case, however, the quality of the final design does not appear to depend significantly on the overall output of the designers' sketch activity or their perceived facility with drawing or visualization.

These results lend further support to the possibility that sketching activity may reflect design thinking for some individuals and not others. If sketching activity is more a result of the designer's need for external visual representation, then designers without that need will likely choose to carry out more of the design process internally. Thus, sketching activity in design appears to be a behavioral output, based the designer's preferences and cognitive abilities. The fact that design outcome appears to be uncorrelated to measures of sketching ability or quantity of sketching activity simply confirms that the design process depends on many skills and many factors, and not just on particular skills in visualization or sketching ability. Being a good or prolific sketcher (a "good artist") or having good mechanical sense (being a "gear head") does not mean that one is also a good designer.

4.4 Role of Sketch Instruction. The findings above suggest that sketching is an important medium for design thinking for some, but not all, designers. Does providing designers with basic

Table 4 Sketches by task and design outcome: $N=32, R_{s}$ $\geqslant 0.296$ for $\alpha=0.10$

\begin{tabular}{lccc}
\hline \hline & \multicolumn{3}{c}{ Correlation coefficient, $R_{s}$} \\
\cline { 2 - 4 } Task & $\begin{array}{c}\text { Project } \\
\text { grade }\end{array}$ & $\begin{array}{c}\text { Which is } \\
\text { most clo } \\
\text { grade }\end{array}$ & $\begin{array}{c}\text { Avg. project } \\
\text { reviewer } \\
\text { ranking }\end{array}$ \\
\hline Bike & -0.039 & 0.074 & -0.163 \\
Hand & 0.027 & 0.084 & -0.167 \\
Box & 0.226 & 0.084 & 0.032 \\
\hline \hline
\end{tabular}

Table 5 Sketch instruction and sketch quantity

\begin{tabular}{lccc}
\hline \hline & $\begin{array}{c}\text { Not } \\
\text { enrolled in } \\
\text { sketch/CAD } \\
\text { course }\end{array}$ & $\begin{array}{c}\text { Enrolled in } \\
\text { sketch/CAD course }\end{array}$ & $\begin{array}{c}\text { Percent } \\
\text { Change } \\
(\%)\end{array}$ \\
\hline $\begin{array}{l}\text { Avg. } \\
\text { sketches } \\
\text { incl. CAD }\end{array}$ & 51 & 73.1 & 43 \\
$\begin{array}{l}\text { Avg. } \\
\text { sketches }\end{array}$ & 35.8 & 57.3 & \\
$\begin{array}{l}\text { Avg. } \\
\text { perspective sketches }\end{array}$ & 11.5 & 24.3 & 60 \\
Avg. bike & 2.7 & 3.0 & 112 \\
Avg. hand & 2.3 & 2.6 & 12 \\
Avg. box & 2.7 & 2.3 & -15 \\
\hline \hline
\end{tabular}

instruction in sketching play a role in how much an individual sketches? Or is it linked to how well he/she does on a project? Table 5 shows the average number of drawings found in student logbooks. The first column is of students who were not taking the concurrent class that included explicit sketching instruction. The second column is of students who were taking the sketching/CAD course. It should be noted that the students enrolled in the sketching/CAD course are self-selected, rather than a random sample. It is possible that those who took the sketching/CAD course generally had a stronger interest in visualization than those not enrolled.

In each case, the average number of drawings is higher for the students who had taken the course with sketch instruction (though not statistically significantly). This was true whether the number of CAD drawings was taken into account or not. CAD drawings and hand sketches were considered separately because CAD drawings were often used more as a later stage communication tool rather than a thinking sketch, and it was assumed that the students in the drawing course would be more facile with CAD tools because they had been exposed to CAD software tools. Perspective drawings, in particular, are of interest because they likely reflect some skill in sketching. Overall, it appears that the explicit instruction of sketching may result in higher sketching output, though this is not conclusive. The lack of significance in the difference is largely due to the large variance in the number of sketches produced, indicating again that sketch activity depends on many factors besides sketching skill.

The last three rows show average sketching skill ratings for the two populations. It should also be noted that students who had sketching instruction started out with somewhat higher scores for the survey tasks for the bike and hand tasks, but not for the box task. This illustrates the relative initial disparities between the two populations.

4.5 Sketching and Teams. Finally, this study examined the role of sketching skill in the context of team project documentation. Teams can divide their work in a number of ways, and presumably one of the motivations for assigning certain tasks is based on functional abilities. The question asked is: Do teams tend to rely on the "best" drawer for accomplishing the drawings in their group project documentation? To examine this, we looked at the group project reports submitted by design teams.

Each team was required to submit a report on their project design, including an illustrated morphology chart with sketches of possible design alternatives, and a detailed sketch of their final project idea. It was assumed that teams would take one of two tacks in creating this report: (i) an individual "scribe" would draw up the report, presumably with input from other team members, or (ii) team members would "share" the work roughly equally whereby each team member would produce one section of the report and aggregate the sections at the end.

In this course, students were permitted to self-select their teams 
Table 6 Comparison of sketching skills for drawers on project teams

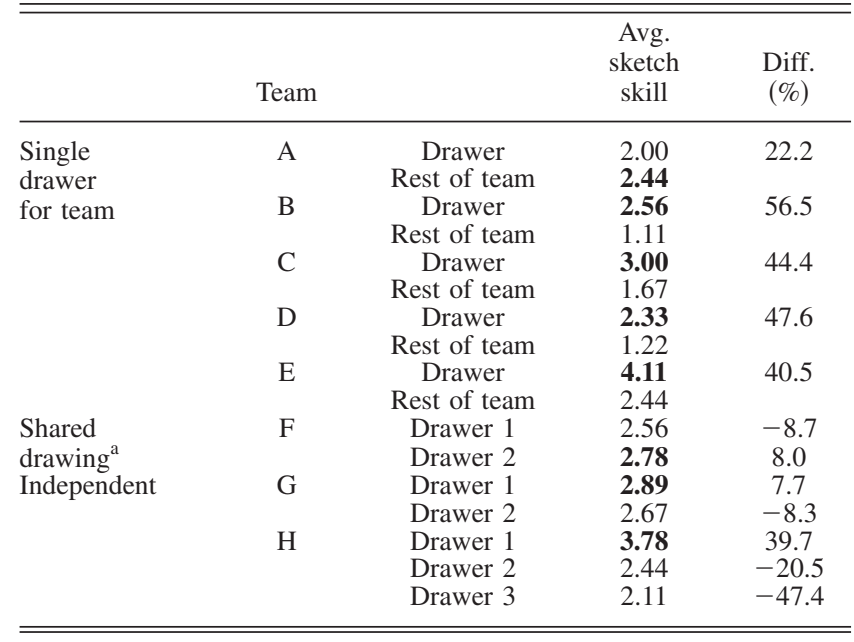

${ }^{\mathrm{a} C}$ Complete data not available for one team.

and also had the option to work individually. Of the 21 projects in the course, there were nine project teams with two to four members, and twelve individual projects.

It was hypothesized that if teams opted for a designated scribe to create the group reports, they would likely choose the team member with the highest-rated drawing skills to make the sketches. Two of the nine groups followed a scribe model (teams $\mathrm{A}$ and $\mathrm{B}$ in Table 6) in which one team member handwrote and produced drawings and text for the shared report, and in one of these teams, the scribe was the strongest drawer on the team. It was also hypothesized that if a team shared the report creation duties among its members, the strongest drawer would be responsible for the sketching aspects, leaving the nonsketching portions to the other members of the team who had lower sketching skill. Five of the nine groups followed such a shared model of report creation (teams C-F, plus another team for whom complete data were unavailable). In three of these cases, a single person was the "designated sketcher" (teams C-E), and indeed, in each of these cases, this individual had the highest average sketch scores. In the other two teams (team F plus the team with incomplete data), team members shared sketching duties equally. Interestingly, the two remaining teams (teams $\mathrm{G}$ and $\mathrm{H}$ ) followed an altogether unexpected model in which team members created their entire reports individually and submitted them independently of each other.

Table 6 also shows percentage difference in average sketching skill between the drawers and the remaining team members. Interestingly, in teams B-E, the "drawer" on the team had substantially higher ratings than their nondrawer counterparts (40.5$56.4 \%$ higher), meaning that the drawer's skills stood out in comparison to his or her teammates. However, in the case of team $\mathrm{A}$, the difference between the lower rated drawer and his teammates with stronger drawing skills was smaller (22\%), suggesting that the skills in this team were more comparable to each other. Overall, only five of the nine teams had a single drawer, but in four of these five teams this individual had the highest drawing ratings. These results suggest that only some teams rely on a single drawer, but those that do tend to favor the drawer with the strongest skills.

\section{Conclusions}

This preliminary study explored three aspects of sketching skills in engineering design, and the link between various sketch tasks, sketch fluency, and design outcome, as well as connections with sketch instruction and team functional division. The results suggest the following answers to the research questions proposed:
1. What is the nature of sketching skill in the context of engineering design?

All sketching skills are not created equal. Often, sketching is thought of an innate, comprehensive skill, but in the context of engineering design, this study suggests that there are clear differences among various types of sketching skills. It was found that there was virtually no correlation between the mechanical recall drawing task and the visualization sketch tasks, while there were positive but not significant correlations between the other tasks. This implies that the individual tasks require different cognitive skills and that, in particular, mechanical recall (bike task) is somewhat distinct from the other skills. These findings further suggest that the ability to sketch is not entirely task based either, meaning that an individual is only good at some tasks but not others. Sketching ability lies somewhere in between the two extremes. These findings are consistent with Kosslyn's observations of mental imagery ability [19-21].

2. How is sketching ability linked to the design process, in particular, its association with sketch fluency and design outcome?

It had been hypothesized that how much designers sketch may be partly determined by how well they draw, but it may also be based on how much they can work things out without drawing. It was true that those who did well on the hand and box tasks also tended to draw more in their logbooks overall. However, it was found that the mechanical recall task was negatively correlated with the quantity of perspective drawing. Perhaps those students with good mechanical recall ability are able to visualize designs in their heads (without committing to paper) and do not need to sketch well or often. In fact, a common complaint among some students is that they do not want to keep logbooks because their work is already "all in their head." In this study, logbooks were used as a tool for capturing design thinking through sketches and text. Thus, for those students who preferred this mode of "in-myhead" thinking, the logbook activity may not fully reflect their design thinking.

These findings suggest that sketches are only one avenue for designers to represent their thinking. Individuals who do not draw may presumably be doing something else visually or at least cognitively; that is, they are working out things in some other way that is not apparent in their sketch ability or sketch quantity. They make work these things out in their head or in prototypes or through discussing things verbally or in text.

Does better sketching also mean better design? Sketching is often linked to design cognition, and it was thought that the sketching ability might also correlate with engineering design performance. In this particular study, no clear relationship was found between performance on the three sketch tasks surveyed and the design outcomes tested. The chief measures used in this study were total sketch quantity and project grade. This study shows little correlation between the total amount of drawing of any type and the grades received in the course. "Good" sketchers did not necessarily do well on the project or vice versa. One likely explanation is that the engineering design process is complex and requires many different skills, and sketching is only one of these. For example, the engineering project that was examined in this study required not just engineering design skills but also the ability to produce a physical device using machine tools as well as to manage one's time on the project.

These preliminary observations suggest that while sketching activity can reflect design thinking, it is an activity affected by many factors, including drawing skill and visualization ability, and in some cases might even be viewed as a behavioral consequence rather than a key element of design thinking.

3. What is the role of sketch instruction in design outcome?

It was hypothesized that providing students with sketch instruction would lead to them becoming more proficient and possibly more motivated sketchers and engineers. It was found that, on average, students who received sketch instruction did do more 
sketching but with no change on their grades or project rankings. However, this increase in sketching is subject to a good deal of variability, which suggests that the increase could be due to any number of other factors, such as an individual's interest in sketching. Just because a student is given some instruction in sketching does not mean that they will actually be motivated to sketch. It should be mentioned again that the two populations compared were not randomly selected, and that the students who took the sketch/CAD course in question began with higher facility in sketching than their counterparts who did not enroll in the sketch/ CAD course.

4. How does sketching skill relate to how a team accomplishes its group work?

It was surmised that those with generally stronger sketching skills would be tapped for drawing duties in team project documentation because of their stronger skills. Of the five teams in which a single drawer produced sketches for the entire team, four employed the strongest sketcher for the job. However, four other teams chose to share drawing duties equally or conduct their work altogether independently. This suggests that teams who opt to select a single individual to complete drawing tasks tend to assign the tasks to the strongest drawer.

\section{Future Work}

Design is a complex activity with many potential factors that can influence its outcome. In particular, it is difficult to tease out potentially confounding variables in the design process and in the nature of the designers themselves. In this study, we considered only the role of sketching ability in the design process. Sketching activity may provide a tool with which to observe design thinking. What motivates a particular designer to use sketches in design? Future work should examine other potentially relevant factors that may affect sketching behavior, such as the role of an individual's motivation or personality, and the nature of a design task.

Implications for Engineering Design Education. Many engineering undergraduates in the United States are provided with instruction in drafting and $\mathrm{CAD}$, but it is less common to teach sketching skills for concept generation and exploration. CAD tools are typically used in the later stages of the design process [33], when ideas are more solidified. In the initial stages of design, when flexibility is important, the designer's ability to quickly sketch and visualize ideas may play a more important role.

The general philosophy is that students need visualization skills in the same way they need math or verbal skills, and that emphasis should be placed on sketching and ideation techniques in engineering education. For example, Stanford University offers a mandatory course in "visual thinking" [3] for mechanical engineering undergraduates, and mechanical engineering students at Caltech are encouraged to take the visualization course described in this paper.

This work suggests that educators should be cognizant of the type of sketching that is being taught. Sketching in engineering design is not merely the ability to draw something accurately or realistically as in drafting, but the ability to represent and generate novel engineering solutions.

\section{Acknowledgment}

The authors gratefully acknowledge Prof. Joel Burdick, the instructor of the introductory engineering design course at the California Institute of Technology, and the design students who are the basis of this research.

\section{References}

[1] Ullman, D. G., Wood, S., and Craig, D., 1990, "The Importance of Drawing in the Mechanical Design Process," Comput. Graph., 14(2), pp. 263-274.

[2] Verstijnen, I. M., van Leeuwen, C., Goldschmidt, G., Hamel, R., and Hennessey, J. M., 1998, "Sketching and Creative Discovery," Des. Stud., 19(4), pp. 519-546.

[3] McKim, R. H., 1980, Experiences in Visual Thinking, PWS Publishers, Boston.

[4] Schön, D. A., and Wiggins, G., 1992, "Kinds of Seeing and Their Functions in Designing," Des. Stud., 13(2), pp. 135-156.

[5] Goel, V., 1995, Sketches of Thought, MIT Press, Cambridge, MA.

[6] Kavakli, M., Scrivener, S. A. R., and Ball, L. J., 1998, "Structure in Idea Sketching Behaviour,” Des. Stud., 19(4), pp. 485-517.

[7] Nagai, Y., and Noguchi, H., 2003, "An Experimental Study on the Design Thinking Process Started From Difficult Keywords: Modeling the Thinking Process of Creative Design," J. Eng. Design, 14(4), pp. 429-437.

[8] Oxman, R. E. O. a. R. M., 1992, "Refinement and Adaptation in Design Cognition," Des. Stud., 13(2), pp. 117-134.

[9] Suwa, M., and Tversky, B., 1997, "What Do Architects and Students Perceive in Their Design Sketches? A Protocol Analysis," Des. Stud., 18(4), pp. 385403.

[10] Romer, A., Leinert, S., and Sachse, P., 2000, "External Support of Problem Analysis in Design Problem Solving," Res. Eng. Des., 12(3), pp. 144-151.

[11] Goldschmidt, G., 1991, "The Dialectics of Sketching," Creativity Research Journal, 4(2), pp. 123-143.

[12] Cross, N., 1999, "Natural Intelligence in Design," Des. Stud., 20(1), pp. 2539.

[13] Shah, J., Vargas-Hernandez, N., Summers, J., and Kulkarni, S., 2001, "Collaborative Sketching (C-Sketch): An Idea Generation Technique for Engineering Design," J. Creat. Behav., 35(3), pp. 168-198.

[14] Tovey, M., Porter, S., and Newman, R., 2003, "Sketching, Concept Development and Automotive Design," Des. Stud., 24(2), pp. 135-153.

[15] Chusilp, P., and Jin, Y., 2006, "Impact of Mental Iteration on Concept Generation," ASME J. Mech. Des., 128(1), pp. 14-25.

[16] Goldschmidt, G., 1994, "On Visual Design Thinking: The vis Kids of Architecture," Des. Stud., 15(2), pp. 158-174.

[17] Purcell, A. T., and Gero, J. S., 1998, "Drawings and the Design Process," Des. Stud., 19(4), 389-430.

[18] Cham, J. G., and Yang, M. C., 2005, "Does Sketching Skill Relate to Good Design?" Proc. of IDETC/CIE 2005 ASME 2005 International Design Engineering Technical Conferences \& Computers and Information in Engineering Conference, Long Beach, CA, ASME, New York.

[19] Kosslyn, S. M., 1984, "Mental Imagery Ability," Introduction to the Psychology of Intelligence, Sternberg, R. J., ed., Erlbaum Associates, Hillsdale, NJ.

[20] Kosslyn, S. M., Van Kleeck, M. C., and Kirby, K. N., 1990, "A Neurologically Plausible Model of Individual Differences in Visual Mental Imagery," Imagery: Current Developments, P. J. Hampson, D. E. Marks, and J. T. E. Richardson, eds., Routeledge, London.

[21] Kosslyn, S. M., 1994, Image and Brain: The Resolution of the Imagery Debate, MIT Press, Cambridge, Mass.

[22] Gardner, H., 1993, Multiple Intelligences: The Theory in Practice, Basic Books, New York.

[23] Katzenbach, J. R., and Smith, D. K., 1993, The Wisdom of Teams: Creating the High-Performance Organization, Harvard Business School Press, Boston.

[24] Ferguson, E. S., 1992, Engineering and the Mind's Eye, MIT Press, Cambridge, MA.

[25] van der Lugt, R., 2005, "How Sketching Can Affect the Idea Generation Process in Design Group Meetings," Des. Stud., 26(2), pp. 101-122.

[26] McGown, A., Green, G., and Rodgers, P. A., 1998, "Visible Ideas: Information Patterns of Conceptual Sketch Activity,” Des. Stud., 19(4), pp. 431-453.

[27] Rodgers, P. A., Green, G., and McGown, A., 2000, "Using Concept Sketches to Track Design Progress," Des. Stud., 21(5), pp. 451-464.

[28] Schütze, M., Sachse, P., and Romer, A., 2003, "Support Value of Sketching in the Design Process," Res. Eng. Des., 14(2), pp. 89-97.

[29] Song, S., and Agogino, A. M., 2004, "Insights on Designers' Sketching Activities in Product Design Teams," 2004, ASME Design Engineering Technical Conference, Salt Lake City.

[30] Yang, M. C., 2004, "An Examination of Prototyping and Design Outcome," 2004 ASME Design Engineering Technical Conferences, Salt Lake City.

[31] Ruder, J., and Sobek, D. K., 2005, "Student System Level Design Activities: An Empirical Pilot Study on Improving Design Outcomes," ASME 2005 International Design Engineering Technical Conferences, Long Beach, CA.

[32] Siegel, S., 1956, Nonparametric Statistics for the Behavioral Sciences, McGraw-Hill, New York.

[33] Tovey, M., 1989, "Drawing and CAD in Industrial Design," Des. Stud., 10(1), pp. 24-39. 